\title{
Effect of Age on Motor Fitness Parameters
}

\author{
Yuvraj Singh Ranawat ${ }^{1 *}$, Dr. Um Singh Rathore ${ }^{2}$
}

\section{ABSTRACT}

The present paper is to study the effect of age on motor fitness of university level players. The sample consists of 450 university level players from three universities of Udaipur. The Aapher fitness test is used as tools of the study. All the university level players were categorized into three age groups namely 18-20, 21-24 and 25-27 years. The one way ANOVA was used and results indicate that there is significant effect of socio-economic status on motor fitness of university level players.

Keywords: Age, Motor Fitness, Sports

The term "motor fitness" is most often used synonymously with physical fitness by the physical educators, but it is very important for the physical education student $s$ to know the basic difference between physical fitness and motor fitness. Physical fitness is used to denote only four basic fitness components (muscular strength, muscular endurance, cardiovascular endurance and flexibility), whereas motor fitness is a more comprehensive term which includes all the ten fitness components like four fitness, one of the health related fitness and five motor performance components, power, speed, agility, balance and reaction time, which is important for the success in sports. In other words, motor fitness refers to the efficiency of basic movements and also to the addition of physical fitness. Sports performance is indeed an aspect of complex human performance, which has several dimensions. Hence, several disciplines of sports sciences are required to work in a coordinated manner to explore the nature and the process of improving performance In the last few decades several disciplines of sports sciences have established e.g. sports medicine, sports physiology, sports training, sports bio-mechanics, sports psychology, sports pedagogy, sports nutrition and so on. These sports sciences work as one integrated unit to give super sports performance.

Singh (2003) conducted a study of physical fitness status of students of Department of Physical Education, Punjabi University Chandigarh and Kurukshetra. He collected data on 34 male subjects and 27 female by using AAHPER Physical Fitness Test. The students of Kurukshetra University were found superior on over all physical fitness status whereas girls of Punjab University were significantly better than Kurukshetra in speed and agility components. Ho ever, no significant difference was observed in overall physical fitness between the 'subjects of both the universities.

\footnotetext{
${ }^{1}$ Research Scholar, Department of Physical Education, Mohanlal Sukhadia University, Udaipur, India

${ }^{2}$ Senior Lecturer \& Head, Department of Physical Education, B.N.P.G. College, Udaipur, India

*Responding Author

Received: June 01, 2017; Revision Received: June 24, 2017; Accepted: June 30, 2017
}

(C) 2017 Ranawat, Y.S, \& Rathore, U.S; licensee IJIP. This is an Open Access Research distributed under the terms of the Creative Commons Attribution License (www.creativecommons.org/licenses/by/2.0), which permits unrestricted use, distribution, and reproduction in any Medium, provided the original work is properly cited. 
Sharma (2004) conducted a study to construct and standardise motor fitness for elementary school children of Delhi. His sample included five hundred boys and girls. The study was conducted in two phases. In the first phase, he developed motor fitness battery by using factor analyses technique namely, (i) Softball throw, (ii) Toe touching, (iii) Double foot balance, (iv) $50 \mathrm{Mt}$. Dash, (v) $800 \mathrm{Mt}$. run/walk for girls scale on all the five components of motor fitness for future use.

\section{Objective}

- To study the effect of socio-economic on physical fitness of university level players.

\section{Hypothesis}

- There is no significant effect of socio-economic on physical fitness of university level players.

\section{Sample}

A sample of 450 university level players between age group of 18-27 years was randomly selected through survey method from three universities namely from Mohanlal Sukhadia University, Udaipur Janaradan Rai Nagar University, Udaipur Maharana Pratap University of Agriculture and Technology, Udaipur. The male players were selected randomly from all the three universities. Only those players were selected who had participated at university level tournaments either in individual field sport of team sport event.

\section{Inclusion Criteria}

To select the subject following criteria of inclusion were fixed by the researcher:

i. Subject must have represented at university level tournament.

ii. Subject must have participated as a member of the college team in field games.

iii. Subject should be of male gender.

iv. Subject's age should be 18 years to 27 years

\section{Tools of the study}

\section{Motor Fitness Components}

For measuring motor fitness the AAPHER test was used The following motor fitness components were selected:

\section{Sit ups}

Tools

Hard floor and stopwatch.

\section{Description}

The individual expected to lie on his back with his bowed knees, it ought to be contemplated that the feet on the floor and impact points ought not in excess of 12 crawls from the hindquarters. It ought to be likewise dealt with the edge at the knees ought not in excess of 90 degrees. The individual needs to put his hands on the rear of his neck with fingers shut and elbows set soundly on the floor. His feet ought to be held by the scorer to keep them in contact with the surface. The individual fixes his muscular strength and brings his head and elbows forward as he twists up, at long last contacting elbows to knees. This activity establishes one sit-up. The student re-visitations of the beginning situation with his elbows on a superficial level before he sits up once more. The clock gives the sign "prepared go," and the sit-up execution is begun "go." Performance is halted on "stop." The quantity of effectively executed sit-ups acted in 60 seconds will be the score. 


\section{Rules}

- Just a single preliminary will be permitted except if the instructor accepts the understudy has not had a reasonable chance to perform.

- No resting is allowed between sit-ups.

- No sit-ups will be included in which the student doesn't (a) keep the fingers fastened behind the neck; (b) present the two elbows in beginning to sit up without pushing off the floor with an elbow; or (c) re-visitation of beginning situation, with elbows level Scoring on a superficial level, before sitting up once more.

Record the quantity of effectively executed sit-ups the student can do in 60 seconds. A foul invalidates the mean that sit-up. The watch is begun "go" and halted on "stop"

\section{Shuttle Run}

\section{Tool}

Two wooden block having size of 2 inches $\mathrm{x} 2$ inches $\mathrm{x} 4$ inches with a stopwatch. Players should wear sports shows.

\section{Description}

Two equal lines are set apart on the floor 30 feet separated. The width of a guideline volleyball court fills in as an appropriate region. Spot the squares of wood behind one of the lines. The student begins from behind the other line. On the sign "Prepared? Go!" the student hurries to the squares, gets one, runs back to the beginning line, and places the square behind the line; he at that point runs back and gets the subsequent square, which he conveys back over the beginning line. On the off chance that the scorer has two stopwatches or one with a brief moment clock, it is desirable over have two students running simultaneously. To kill the need of restoring the squares after each race, start the races on the other hand, first from behind one line and afterward from behind the other.

\section{Rules}

- Permit two preliminaries with some rest between.

\section{Scoring}

Record the hour of the better of the two preliminaries to the closest 10th of a second.

\section{Standing Long Jump}

\section{Tools}

Jumping pit and measurement tape.

\section{Description}

Understudy remains with the feet a few inches separated and the toes simply behind the departure line. Preliminary to hopping, the student swings the arms in reverse and curves the knees. The bounce is cultivated by all the while broadening the knees and swinging forward the arms.

\section{Rules}

- Permit three preliminaries.

- Measure from the departure line to the heel or other aspect of the body that contacts the floor closest the departure line.

- At the point when the test is given inside, it is helpful to tape the measuring tape to the floor at right edges to the departure line and have the students hop along the tape. The scorer stands aside and watches the imprint to the closest inch.

\section{Scoring}

Record the best of the three preliminaries in feet and creeps to the closest inch and converted in $\mathrm{cm}$ through conversion formula. 


\section{0 yards dash}

\section{Tools}

Split second timer.

\section{Description}

It is desirable over direct this test to two students all at once. Have both take positions behind the beginning line. The starter will utilize the orders "Are you prepared?" and "Go!" The last will be joined by a descending compass of the starter's arm to give a visual sign to the clock, who remains toward the end goal.

\section{Rules}

- The score is the measure of time between the starter's sign and the moment the Scoring understudy crosses the end goal.

Record in seconds to the closest 10th of a second.

\section{Pull ups}

\section{Tools}

A doorway gym bar.

\section{Description}

The bar should be high enough so that the pupil can hang with his arms and legs fully extended and his feet free of the floor. He should use the overhand grasp. After assuming the hanging position, the pupil raises his body by his arms until his chin can be placed over the bar and then lowers his body to a full hang as in the starting position. The exercise is repeated as many times as possible.

\section{Rules}

- Allow one trial unless it is obvious that the pupil has not had a fair chance.

- The body must not swing during the execution of the movement. The pull must in no way be a snap movement. If the pupil starts swinging, check this by holding your extended arm across the front of the thighs.

- The knees must not be raised and kicking of the legs is not permitted.

\section{Scoring}

Record the number of completed pull-ups to the nearest whole number.

\section{0 yard walk and run}

\section{Tools}

Running Track and stopwatch.

\section{Description}

Pupil uses a standing start. At the signal "Ready? Go!" the pupil starts running the 600-yard distance. The running may be interspersed with walking. It is possible to have a dozen pupils run at one time by having the pupils pair off before the start of the event. Then each pupil listens for and remembers his partner's time as the latter crosses the finish. The timer merely calls out the times as the pupils cross the finish.

\section{Rules}

- Walking is permitted, but the object is to cover the distance in the shortest possible time.

\section{Scoring}

Record in minutes and seconds. 


\section{Method of Data Collection}

First of all on the basis of Socio-economic the sample was categorized into five levels. To gather the information the analyst visited different universities and actually met all the understudies. The researcher clarified plainly in Hindi language about the motivation behind the investigation alongside the technique of the test. Time taken to finish the undertaking by every one of the subject was 3-4 minutes. A large portion of the subjects reacted in certain way with incredible excitement and straightforwardness. All the university level players were categorized into three age groups namely 18-20, 21-24 and 25-27 years. All subjects were amassed and a concise portrayal was given about the reason and prerequisite of testing methods of the investigation to cause them to comprehend about what they are really needed to do during the analysis or the examination. All subjects concurred deliberately to coordinate in the testing technique which was to be disclosed to them.

\section{Statistical Analysis}

To analyse the data, various statistical methods was applied ANOVA. The level of significance was set at 0.05 . All the statistical calculations were done through SPSS (version 21.0).

\section{RESULTS AND DISCUSSION}

The following table shows the effect of Age on Motor Fitness Parameters.

Table 1

Effect of Age on Motor Fitness Parameters

\begin{tabular}{|c|c|c|c|c|c|c|}
\hline & & $\begin{array}{l}\text { Sum of } \\
\text { Squares }\end{array}$ & df & $\begin{array}{l}\text { Mean } \\
\text { Square }\end{array}$ & $\mathbf{F}$ & Sig. \\
\hline \multirow{3}{*}{$\begin{array}{l}\text { Sit-Ups } \\
\text { (Legs Strength) }\end{array}$} & Between Groups & 869.531 & 2 & 434.766 & \multirow[t]{3}{*}{57.983} & \multirow[t]{3}{*}{0.000} \\
\hline & Within Groups & 3351.689 & 447 & 7.498 & & \\
\hline & Total & 4221.220 & 449 & & & \\
\hline \multirow{3}{*}{$\begin{array}{l}\text { Shuttle Run } \\
\text { (Agility) }\end{array}$} & Between Groups & 15.066 & 2 & 7.533 & \multirow[t]{3}{*}{20.099} & \multirow[t]{3}{*}{0.000} \\
\hline & Within Groups & 167.535 & 447 & 0.375 & & \\
\hline & Total & 182.601 & 449 & & & \\
\hline \multirow{3}{*}{$\begin{array}{l}\text { Standing Long Jump } \\
\text { (Explosive } \\
\text { Strength/Power) }\end{array}$} & Between Groups & 0.644 & 2 & 0.322 & \multirow[t]{3}{*}{23.072} & \multirow[t]{3}{*}{0.000} \\
\hline & Within Groups & 6.237 & 447 & 0.014 & & \\
\hline & Total & 6.881 & 449 & & & \\
\hline \multirow{3}{*}{$\begin{array}{l}50 \text { yard dash } \\
\text { (Speed) }\end{array}$} & Between Groups & 24.719 & 2 & 12.360 & \multirow[t]{3}{*}{11.837} & \multirow[t]{3}{*}{0.000} \\
\hline & Within Groups & 466.740 & 447 & 1.044 & & \\
\hline & Total & 491.460 & 449 & & & \\
\hline \multirow{3}{*}{$\begin{array}{l}\text { Pull-ups } \\
\text { (Hands Strength) }\end{array}$} & Between Groups & 287.711 & 2 & 143.855 & \multirow[t]{3}{*}{26.385} & \multirow[t]{3}{*}{0.000} \\
\hline & Within Groups & 2437.154 & 447 & 5.452 & & \\
\hline & Total & 2724.864 & 449 & & & \\
\hline \multirow{3}{*}{$\begin{array}{l}600 \text { Yard Run \& Walk } \\
\text { (Endurance) }\end{array}$} & Between Groups & 1712.012 & 2 & 856.006 & \multirow[t]{3}{*}{21.432} & \multirow[t]{3}{*}{0.000} \\
\hline & Within Groups & 17853.252 & 447 & 39.940 & & \\
\hline & Total & 19565.264 & 449 & & & \\
\hline
\end{tabular}

The above table shows that the F-ratio was found to be 434.766 which is significant at 0.01 level. It infers that there is significant effect of Age on Sit-Ups (Legs Strength) of Physical Fitness Parameters.

The above table reflects that the F-ratio was found to be 20.099 which is significant at 0.01 level. It infers that there is significant effect of Age on Shuttle Run (Agility) of Physical Fitness Parameters. 
The above table visualizes that the F-ratio was found to be 11.837 which is significant at 0.01 level. It infers that there is significant effect of Age on 50 yard dash (Speed) of Physical Fitness Parameters.

The above table indicates that the F-ratio was found to be 26.385 which is significant at 0.01 level. It infers that there is significant effect of Age on Pull-ups (Hands Strength) of Physical Fitness Parameters.

The above table presents that the F-ratio was found to be 21.432 which is significant at 0.01 level. It infers that there is significant effect of Age on 600 Yard Run \& Walk (Endurance) of Physical Fitness Parameters.

\section{CONCLUSION}

The hypothesis "There is no significant effect of socio-economic on physical fitness of university level players" is rejected.

\section{Acknowledgments}

The author appreciates all those who participated in the study and helped to facilitate the research process.

Conflict of Interests: The author declared no conflict of interests.

\section{REFERENCES}

Chauhan DS. The Relationship between Anthropometric Variables and Explosive Arm Strength of Volley ball Players. Journal of Sports and Sports Science. 2005; 28(2):5-13.

Fredrick Cozen W. A study of stature in relation to physical performance, Research Quarterly. 1930, 35.

Gabbett TJ, Jenkins DG, Abernethy B. Physiological and anthropometric correlates of tackling ability in junior elite and subelite rugby league players. J Strength Cond Res. 2010; 24(11):2989-95.

Manmoon kaur Lamba. A comparative study of Selected Physical components and Physiological Parameters of offencive and Defensive Hockey Players of College level”. (Unpublished thesis Jiwaji University), 1980.

Mirkov DM, Kukolj M, Ugarkovic D, Koprivica VJ, Jaric S. Development of anthropometric and physical performance profiles of young elite male soccer players: a longitudinal study. J Strength Cond Res. 2010; 24(10):2677-82.

Osborough CD, Payton CJ, Daly DJ. Relationships between the front crawl stroke parameters of competitive unilateral arm amputee swimmers, with selected anthropometric characteristics, Appl Biomech. 2009; 25(4):304-12.

Pease Dale G. Relationship of selected Hand wrist measurement to ability to shoot in basket Ball, Perceptual and motor skills. 1981; 52:793.

Pelin C, Kurkcuoglu A, Ozener B, yazici AC. Anthropometric characteristics of young Turkish male athlepes, Coll Antropol. 2009; 33(4):1057-63.

Sharma SM. Specific Physical Fitness Determinants for Badminton Players Established in U.G.C. National Seminar on Physical Education and Sports, 2004, 28.

Singh MB. A Study of Physical Fitness Status of Students of Department of Phy. Edu. of P U Patiala. Thesis submitted to N.S.N.I.S, 2003, 
How to cite this article: Ranawat, Y.S, \& Rathore, U.S (2017), Effect of Age on Motor Fitness Parameters, International Journal of Indian Psychology, Volume 4, (3), DIP:18.01.161/20170403, DOI:10.25215/0403.161 